Article

\title{
Innovative Use of Sheep Wool for Obtaining Materials with Improved Sound-Absorbing Properties
}

\author{
Simona Ioana Borlea (Mureşan) ${ }^{1}$, Ancuţa-Elena Tiuc ${ }^{1, *(\mathbb{D})}$, Ovidiu Nemeşs $1,2, *$ (i), \\ Horaţiu Vermeşan ${ }^{1}$ (1) and Ovidiu Vasile ${ }^{3}$ (D) \\ 1 Faculty of Materials and Environmental Engineering, Technical University of Cluj-Napoca, Cluj-Napoca, \\ 28 Memorandumului Street, 400114 Cluj-Napoca, Romania; Ioana.Muresan@staff.utcluj.ro (S.I.B.M.); \\ horatiu.vermesan@imadd.utcluj.ro (H.V.) \\ 2 National Institute for Research and Development in Environmental Protection, 294 Blvd Splaiul \\ Independentei, Sector 6, 060031 Bucharest, Romania \\ 3 Department of Mechanics, Politehnica University of Bucharest, 313 Splaiul Independentei, 060042 Bucharest, \\ Romania; ovidiu.vasile@upb.ro \\ * Correspondence: ancuta.tiuc@imadd.utcluj.ro (A.-E.T.); ovidiu.nemes@sim.utcluj.ro (O.N.); \\ Tel.: +40-756-102-923 (A.-E.T.); +40-724-072-598 (O.N.)
}

Received: 28 November 2019; Accepted: 1 February 2020; Published: 4 February 2020

\begin{abstract}
In recent years, natural materials are becoming a valid alternative to traditional sound absorbers due to reduced production costs and environmental protection. This study explores alternative usage of sheep wool as a construction material with improved sound absorbing properties beyond its traditional application as a sound absorber in textile industry or using of waste wool in the textile industry as a raw material. The aim of this study was to obtain materials with improved sound-absorbing properties using sheep wool as a raw material. Seven materials were obtained by hot pressing $\left(60 \div 80^{\circ} \mathrm{C}\right.$ and $\left.0.05 \div 6 \mathrm{MPa}\right)$ of wool fibers and one by cold pressing. Results showed that by simply hot pressing the wool, a different product was obtained, which could be processed and easily manipulated. The obtained materials had very good sound absorption properties, with acoustic absorption coefficient values of over 0.7 for the frequency range of $800 \div 3150 \mathrm{~Hz}$. The results prove that sheep wool has a comparable sound absorption performance to mineral wool or recycled polyurethane foam.
\end{abstract}

Keywords: sheep wool recovery; acoustic materials; sound absorption coefficient

\section{Introduction}

From a sustainable development perspective, an important goal is to choose raw materials that are easily recyclable and renewable as well as locally available and environmentally friendly. This includes timber, clay, stone, straw, bio-based fibers, and sheep wool, provided that any further processing is carried out with low energy consumption.

The origin of these materials can be vegetable or animal so that their manufacturing has a low environmental impact due to the energy saved in the production process [1]. The use of natural fibers as raw material for acoustic applications have been intensively studied [2-14], especially in recent years. Many industries are moving toward natural material-based, environmentally friendly products $[15,16]$. This may be due to the fact that the energy required to process these types of materials is lower compared to that required for synthetic materials. For instance, processing $1 \mathrm{~m}^{3}$ of sheep wool insulation produces almost $5.4 \mathrm{~kg}$ of $\mathrm{CO}_{2}$, whereas the quantity of $\mathrm{CO}_{2}$ produced is $135 \mathrm{~kg}$ in the 
case of mineral wool [17]. Thus, the environmental impact when using these types of materials is low, and there is no negative effect on the environment [18].

Many natural materials, such as bamboo, kenaf, sisal, flax, hemp, sheep wool, cork, or coconut fibers, show good sound-absorbing performance and can therefore be used as sound absorbers in acoustic rooms and noise barriers $[19,20]$.

Sheep wool is an easily recyclable, easily renewable, and environmentally friendly source of raw material, which consists of $60 \%$ animal protein fibers, $10 \%$ fat, $15 \%$ moisture, $10 \%$ sheep sweat, and $5 \%$ impurities on average. Zach et al. evaluated the thermal, hygrothermal, and acoustic performance of samples of sheep wool materials. A mixture of sheep wool was mechanically fastened to a reinforcing cloth with varying thickness and density. The results showed that sheep wool was characterized by high hygroscopicity that reached up to $35 \%$ and that sheep wool could therefore be an excellent acoustic insulating material [21].

Del Rey et al. studied sheep wool as a sustainable material for acoustic applications. The materials were made from sheep wool by thermofusion with polyester fibers obtained from recycled polyethylene terephthalate (PET) flakes that acted as a binder (PET fibers melt at $140-150{ }^{\circ} \mathrm{C}$ ). The final material had $80 \%$ sheep wool fibers (first quality, second quality, or blend), and the remaining $20 \%$ was PET fibers. From the measurement results, it was demonstrated that sheep wool with PET fiber was a good sound-absorbing material at medium and high frequencies, with acoustic absorption coefficient values of over 0.5 for the frequency range of $600 \div 3150 \mathrm{~Hz}$ for the best material obtained [1].

Until now, sheep wool has traditionally been used in the textile industry for the manufacturing of conventional woolen products, such as carpets, garments, curtains, covers, and bedding. More recently, they have also been used in the building industry due to their thermal properties. For the fabrication of wool-based building materials, coarse fibers or those fibers that cannot be used in the textile industry are generally used [22]. Wool has good thermal characteristics, with the thermal conductivity of wool panels varying between 0.040 and $0.041 \mathrm{~W} / \mathrm{mK}$ for densities of $25 \div 92.5 \mathrm{~kg} / \mathrm{m}^{3}$ [23].

Sheep wool fibers have a similar size as mineral fibers. A $33 \div 36 \mu \mathrm{m}$ sheep wool fiber would roughly be the same size as PET polyester fibers $(33 \mu \mathrm{m})$ [24] or Kenaf fibers $(36 \mu \mathrm{m})$ [25]. Unlike synthetic fibers, sheep fibers do not have a fixed thickness. Their thickness range has a standard deviation of $2 \mu \mathrm{m}$, according to scientific literature [26]. The fiber diameter also depends on the breed of the sheep.

The surface of wool fibers has many scales, and the fibers can only move on one direction. Under mechanical agitation, friction, and pressure in the presence of moisture and heat, the scale edge of one fiber locks into the interscale gap of another fiber like a "ratchet" mechanism. The fibers interlock and cannot return to their original positions, resulting in irreversible felting shrinkage [27].

Pressed felt is produced from wool or animal hair by mechanical agitation and compression of the fibers in warm, moist conditions [28].

The aim of this study was to analyze the sound absorption coefficient of some materials or structures based on sheep wool as an alternative to the classical (wool felts, mineral wool, or foams) or the new series of improved sound absorbers. The sound absorption capability of sheep wool was measured in an impedance tube. Experimental results indicated the material's excellent performance in the development of building elements for sound absorption with or without the addition of other elements (polyurethane foam, epoxy, or polyester resin).

Compared with the classical acoustic materials existing in the market or in the literature, the ones obtained in this research have the advantage of good properties. They are also environmentally friendly due to the fact that no binders are used, and the working parameters (pressure and temperature) require low energy consumption. These materials with very good acoustic absorption properties can be obtained by hot pressing without the presence of humidity compared to the standard mode of felting. 


\section{Materials and Methods}

\subsection{Materials}

In order to obtain the desired sound-absorbing materials, black merino sheep wool (different shades of black, including dark brown) was used. Figure 1 shows the raw sheep wool $(60 \div 80 \mathrm{~mm}$ length, $18 \div 20 \mu \mathrm{m}$ fineness, ripple of $100 \mathrm{~mm}$, and density of $3.4578 \mathrm{~g} / \mathrm{cm}^{3}$ ). Prior to experiments, the raw wool was washed to remove impurities, sand, and dust, and it was then dried and carded.

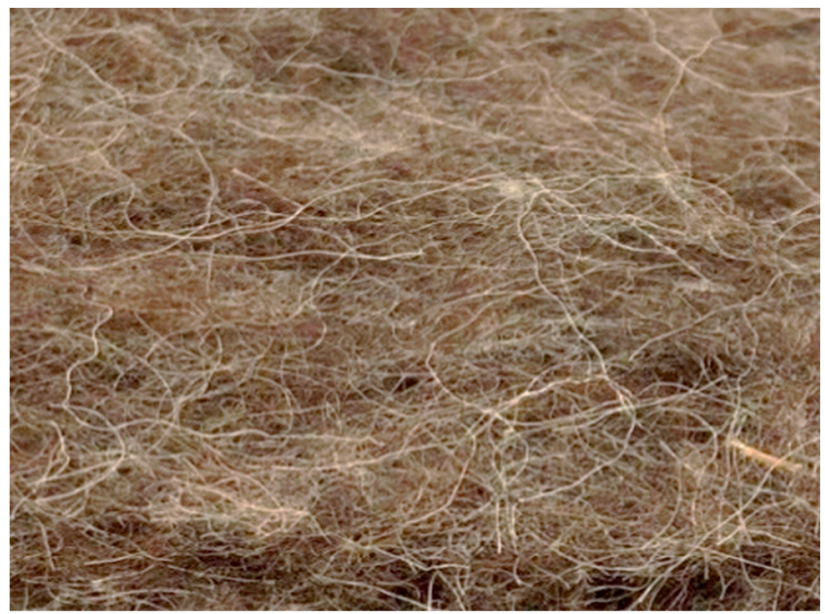

Figure 1. The raw material used: black merino sheep wool.

\subsection{Manufacturing Process}

The samples used in this research were obtained by hot and cold pressing. The mold used to obtain the material samples had a cylindrical shape with two aluminum hot plates (top and bottom). The samples were heated from both sides to obtain a uniform temperature in the mold. The mold was equipped with four thermocouples disposed on the outside, which were connected to a temperature regulator and measured the working temperature. The mold was also fitted with a thermostat to maintain a constant temperature. Figure 2 shows the mold that was used to obtain the material samples.

Because the ability of a material to reduce the acoustic energy depends on its thickness, different wool quantities were considered in order to prepare different sample thicknesses [29].

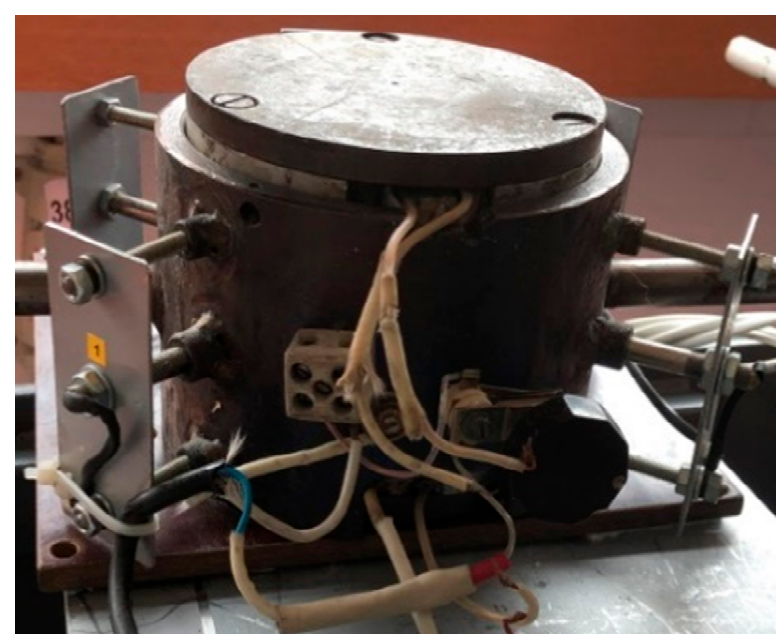

Figure 2. The mold used to obtain material samples by hot pressing [30]. 
The mold for the cold-pressed samples was made of steel in rectangular shape with a lid. To obtain the hot-pressed samples, hot pressing was done in a mold by applying a pressure of $0.05 \div 6 \mathrm{MPa}$ on the material, which was heated to $60 \div 80{ }^{\circ} \mathrm{C}$. When wool fibers are heated, they easily fill the new shape, and the pressure in the mold forces the wool fibers to compress. The obtained samples were kept in the mold under pressure until complete cooling. After this, the mold was opened, and the sample was extracted. The main parameters that were followed for this process were pressure, pressing time, and temperature. The required heat was transferred through the mold walls. The required pressure force was obtained from a manually operated hydraulic press (Unicraft WPP 50 E, Stürmer Machinen Gmbh, Hallstadt, Germany).

Eight sound-absorbing materials were obtained following the procedure described above. The obtained materials were divided into three groups (Figure 3) depending on the embodiment: hot-pressed wool moistened with water (WHW, labelled as A), hot-pressed wool (WH, labelled as B), and cold-pressed wool (WC, labelled as C). Table 1 presents the technical parameters of the obtained material samples.

\begin{tabular}{ccc|} 
Hot pressing $(\mathrm{H})$ & Hot pressing $(\mathrm{H})$ & Cold pressing $(\mathrm{C})$ \\
Sheep wool $(\mathrm{W})$ & Sheep wool $(\mathrm{W})$ & Sheep wool $(\mathrm{W})$ \\
Water $(\mathrm{W})$ & B & C \\
\hline A & B
\end{tabular}

Figure 3. Groups of obtained materials.

Table 1. Technical parameters of the materials obtained.

\begin{tabular}{ccccccc}
\hline Group & Code & $\begin{array}{c}\text { Initial Height } \\
(\mathbf{m m})\end{array}$ & $\begin{array}{c}\text { Final Height } \\
(\mathbf{m m})\end{array}$ & $\begin{array}{c}\text { Temperature } \\
\left({ }^{\circ} \mathbf{C}\right)\end{array}$ & $\begin{array}{c}\text { Pressure } \\
(\mathbf{M P a})\end{array}$ & $\begin{array}{c}\text { Water } \\
(\mathbf{m} \mathbf{)})\end{array}$ \\
\hline \multirow{3}{*}{ A } & WHW40_3_25 & 40 & 1 & 60 & 3 & 25 \\
& WHW80_6_50 & 80 & 2.5 & 70 & 6 & 50 \\
& WHW80_6_75 & 80 & 3 & 80 & 6 & 75 \\
\hline \multirow{2}{*}{ B } & WH120_4 & 120 & 15 & 80 & 4 & - \\
& WH240_4 & 240 & 25 & 80 & 4 & - \\
& WH120_0.05 & 124 & 35 & 80 & 0.05 & - \\
\hline C & WH240_0.05 & 240 & 50 & 80 & 0.05 & - \\
\hline
\end{tabular}

The materials in group A were made of wool by hot pressing (pression 3 and $6 \mathrm{MPa}$ and temperature 60,70 , and $80^{\circ} \mathrm{C}$ ). In order to analyze the influence of humidity on the new materials, three tests were carried out by varying the amount of water used for moistening, i.e., 25, 50, and 75 $\mathrm{mL}$. Results showed that the wool became plastic by wetting, especially at temperatures around $80^{\circ} \mathrm{C}$. It is upon this thermoplastic property that the pressing and elimination of the wrinkles in the wool fiber is based [31]. Thus, sample WHW80_6_75 heated at $80{ }^{\circ} \mathrm{C}$ had the consistency of a plywood with portions of glossy faces.

In the case of materials from group B, the wool was not wetted, and the initial wool layer (120 and $240 \mathrm{~mm}$ ) was hot pressed at 4 and $0.05 \mathrm{MPa}$ at a temperature of $80{ }^{\circ} \mathrm{C}$. Four samples were obtained, the parameters and codes of which are presented in Table 1.

The material constituting group $\mathrm{C}$ was obtained by cold pressing a wool layer with an initial height of $40 \mathrm{~mm}$ at a pressure of $0.003 \mathrm{MPa}$.

\subsection{Methods}

The determination of apparent density was performed according to ISO 845:2006 [32]. The tested samples were cylindrical with a diameter of $63.5 \mathrm{~mm}$ and a specific height for each material. 
The dimensions of the specimens were measured with a $0.1 \mathrm{~mm}$ accuracy. The weight was determined using a laboratory balance with $0.01 \mathrm{~g}$ accuracy. The apparent density of specimens was calculated using the following formula:

$$
\rho=\frac{m}{V}\left[\mathrm{~g} / \mathrm{cm}^{3}\right]
$$

where $m$ is the mass of the sample, and $V$ is the volume of the sample.

The sound absorption coefficient at normal incidence $(\alpha)$ is the quotient between the acoustic energy absorbed by the surface of the test sample and the incident acoustic energy for a plane acoustic wave at normal incidence. ISO 10534-2 standard [33] establishes a test procedure to determine the sound absorption coefficient for normal incidence of acoustic absorbers by means of an impedance tube, two microphone positions, and a digital analysis system signal.

The method of measuring the acoustic absorption coefficient by means of the impedance tube is based on the fact that the reflection coefficient at normal incidence ( $r$ ) can be calculated from the measured transfer function (H12) between two positions of the microphone at different distances from the sample. The transfer function of the incident $\left(H_{I}\right)$ and reflecting waves $\left(H_{R}\right)$ between the microphone positions are defined as follows [34]:

$$
\begin{gathered}
H_{I}=\frac{p_{2 I}}{p_{1 I}}=e^{-j k \cdot\left(x_{1}-x_{2}\right)}=e^{-j k \cdot s} \\
H_{R}=\frac{p_{2 R}}{p_{1 R}}=e^{-j k \cdot\left(x_{1}-x_{2}\right)}=e^{-j k \cdot \mathcal{s}}
\end{gathered}
$$

where $s$ is the distance between the two microphone positions; $x_{1}$ and $x_{2}$ are the distances from the reference point to microphone position 1 and 2 , respectively; $p_{I}$ and $p_{R}$ are the sound pressure propagating in the incident and reflected direction, respectively; and $j k$ is a complex-valued wavenumber.

The transfer function $\left(H_{12}\right)$ for the total sound field can be calculated with the following formula [34]:

$$
H_{12}=\frac{p_{2}}{p_{1}}=e^{-j k \cdot\left(x_{1}-x_{2}\right)}=e^{-j k \cdot s}
$$

The reflection coefficient $(r)$ at the sample surface $(x=0)$ is as follows [33]:

$$
r=\frac{H_{12}-H_{I}}{H_{R}-H_{12}} e^{2 j k \cdot x_{1}}
$$

The sound absorption coefficient at normal incidence is calculated with the following formula [34]:

$$
r=1-|r|^{2}
$$

The $\alpha$ values were ascertained by producing standing waves in a tube with $63.5 \mathrm{~mm}$ diameter, so the tests were performed on circular samples (Figure 4) with a diameter of $63.5 \mathrm{~mm}$. The circular samples were placed at the end of the Kundt's tube Brüel\&Kjaer Type 4206 during each test. Measurements were recorded at the third-octave frequency band within the intervals of $100 \div 3200 \mathrm{~Hz}$ and conducted at an air temperature of $26^{\circ} \mathrm{C}$, relative humidity of $55 \%$, and pressure of $100.5 \mathrm{kPa}$. 


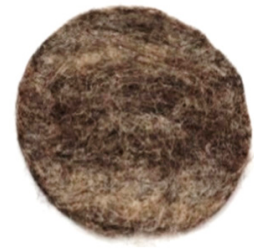

WHW40_3_25

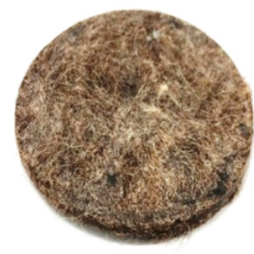

WH120_4

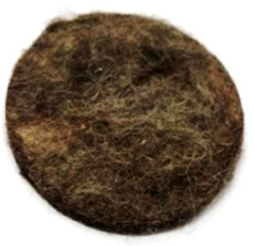

WHW80_6_50

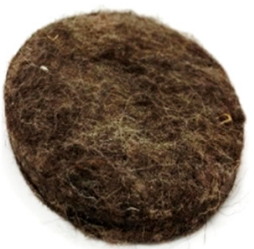

WH240_4

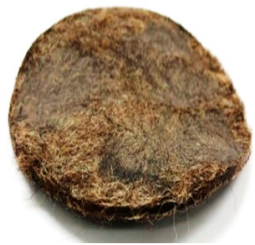

WHW80_6_75

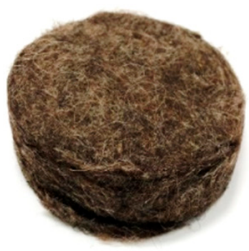

WH120_0.05

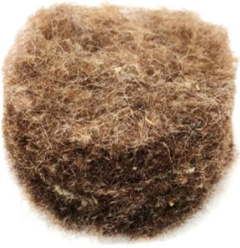

WC40

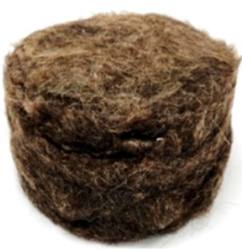

WH240_0.05

Figure 4. Samples prepared for sound absorption coefficient measurement.

\section{Results and Discussion}

\subsection{Results for Apparent Density Tests}

The material density is an important factor for the acoustic absorption of a material. As the density of the material increases, the sound absorption at medium and high frequencies also increases. Increased number of fibers per unit area increases the apparent density. Energy loss increases with the increase in friction surface, thus increasing the sound absorption coefficient [35].

The apparent density determined for the obtained materials is shown in Figure 5. It can be seen that the hot-pressed materials had a much higher density than the cold-pressed materials. The density of the materials made from sheep wool increased with the increase in pressure.

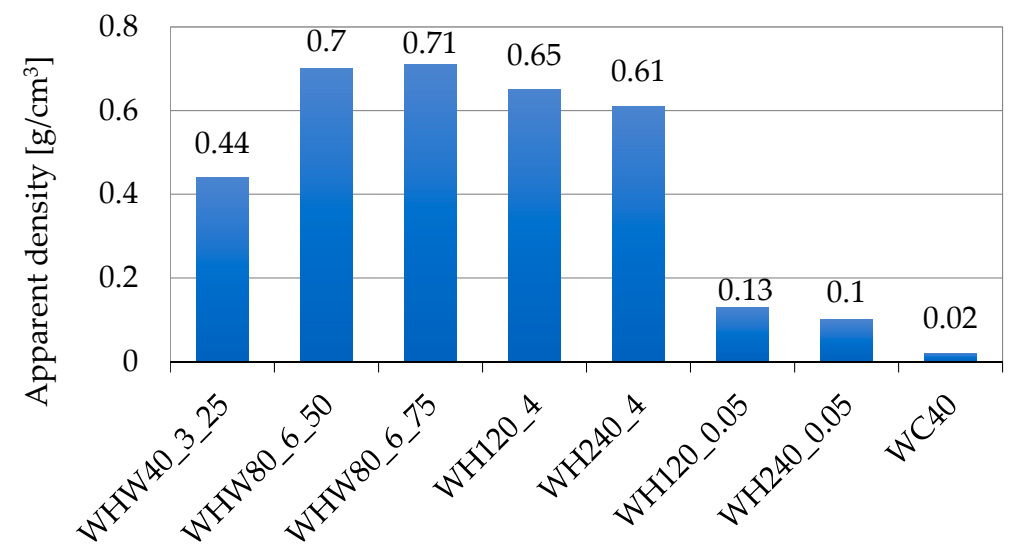

Figure 5. Apparent density values.

\subsection{Results of Acoustic Tests}

The acoustic characterization of the materials was based on the sound absorption coefficient $\alpha$ [36]. This parameter is the ratio of absorbed sound intensity to incident sound intensity on a surface [37]. The potential for materials to absorb sound energy depends on the following factors: density, thickness, porosity, fiber diameter, airflow resistivity, tortuosity, surface impedance, compression, air gap, and multilayers $[19,38]$. 


\subsubsection{The Effect of Material Thickness on the Sound Absorption Coefficient}

This section highlights and discusses the variation in acoustic absorption coefficient with the thickness of materials obtained from hot-pressed sheep wool at $80^{\circ} \mathrm{C}$ and a pressure between 4 and $0.05 \mathrm{MPa}$. The influence of material thickness obtained from compressed sheep wool at a pressure of $4 \mathrm{MPa}$ on the coefficient of acoustic absorption is presented in Figure 6.

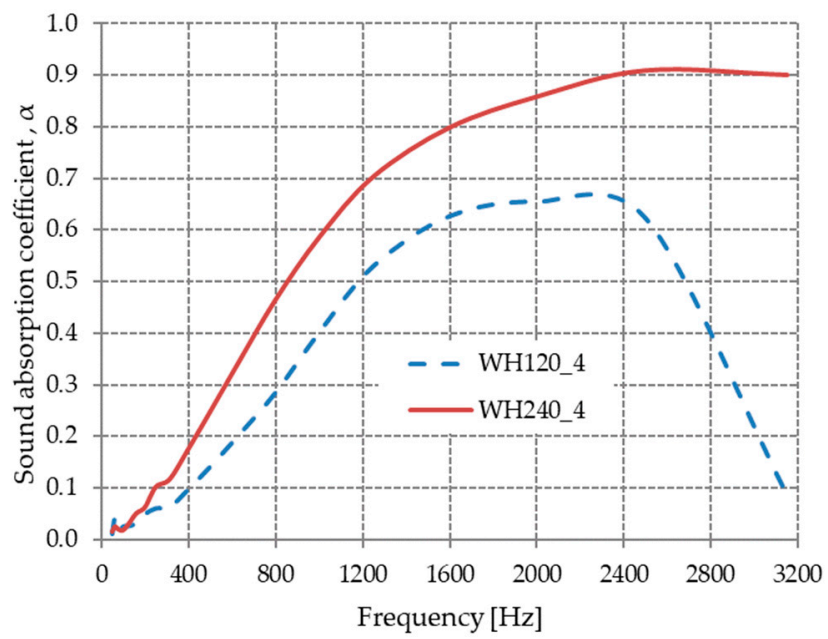

Figure 6. Variation in the acoustic absorption coefficient with the material thickness for WH120_4 and WH240_4.

From Figure 6, it can be observed that material WH240_4 with $25 \mathrm{~mm}$ thickness had an acoustic absorption coefficient greater than WH120_4, which had a smaller thickness (15 mm), over the entire analyzed frequency range.

The thickness of the compressed materials at $0.05 \mathrm{MPa}$ was $35 \mathrm{~mm}$ for material WH120_0.05 and 50 mm for WH240_0.05.

The influence of compressed material thickness on the acoustic properties is shown in Figure 7. It can be observed that the material with the greatest thickness had the highest sound absorption coefficient values over the entire analyzed frequency range.

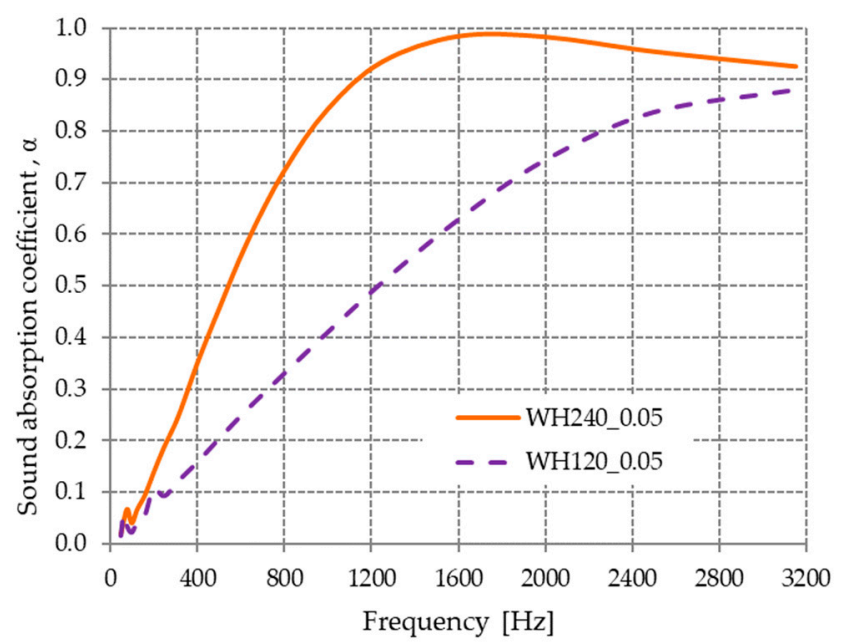

Figure 7. Variation in the acoustic absorption coefficient with the material thickness for WH120_0.05 and WH240_0.05.

The sound absorption coefficient improved by increasing the composite thickness, an aspect that has been demonstrated in the literature [39]. Experimental testing performed on materials such as fiber 
felts, glass wool, paddy straw, textile waste, rubber crumbs, and polyester have all shown an increase in sound absorption with an increase in material thickness, especially at lower frequencies [1,40-43].

An analysis of the sound absorption coefficient values of our hot-pressed, wool-based material (Figures 6 and 7) relative to other wool-based materials reported in the literature showed that the coefficient values were better at comparable thicknesses. The acoustic absorption coefficient values of the obtained materials at the frequency of $1000 \mathrm{~Hz}$ were 0.4 for WH120_4 (15 mm), 0.59 for WH240_4 (25 mm), and 0.84 for WH240_0.05 (50 mm). For other materials made from sheep's wool [21], the coefficient values for different material thicknesses were 0.331 for $20 \mathrm{~mm}, 0.415$ for $30 \mathrm{~mm}$, and 0.7 for $40 \mathrm{~mm}$.

\subsubsection{The Influence of Wool Compression on the Sound Absorption Coefficient}

The studied materials were compressed at 0.05 and $4 \mathrm{MPa}$ starting from an initial height of $240 \mathrm{~mm}$ and $120 \mathrm{~mm}$, respectively, and the influence of the compression of wool fibers on the acoustic absorption coefficient is shown in Figure 8.

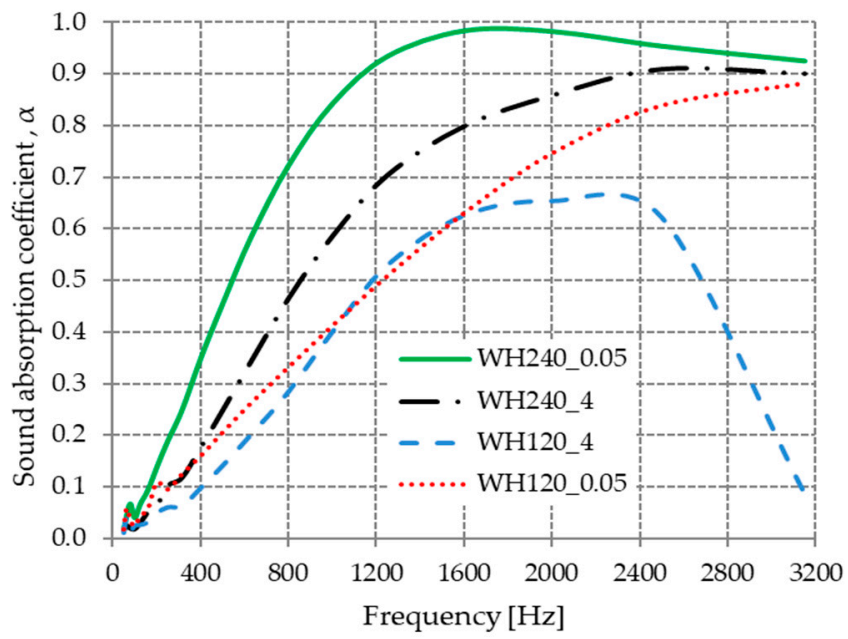

Figure 8. Variation in the acoustic absorption coefficient with the compaction pressure.

The compressed material WH240_0.05 had better sound-absorbing properties at 0.05 MPa with $0.01 \mathrm{~g} / \mathrm{cm}^{3}$ density than the compressed material WH240_4 at $4 \mathrm{MPa}$ with $0.61 \mathrm{~g} / \mathrm{cm}^{3}$ density. For the materials marked as WH120_0.05 and WH120_4, the acoustic absorption coefficient had better values in the frequency range of $50 \div 1100 \mathrm{~Hz}$ and $1600 \div 3200 \mathrm{~Hz}$ compared to the compressed material at a lower pressure (WH120_0.05). This can be explained by the fact that the fibers within the material are brought closer to each other during compression. Thus, the material becomes more compact, the open porosity decreases, and the compression leads to a decrease in the thickness of the material [44].

The acoustic absorption properties of fibrous mat decrease during compression because the material thickness decreases during compression. Compression tests done on polyester fiber showed a drop in the absorption coefficient when the fibrous mat was compressed [45]. Fouladi et al. and Nor et al. they stated that compression affects the physical parameters of materials, including the flow resistivity, tortuosity, and porosity. These parameters define the link between the acoustic medium and the matrix $[46,47]$.

\subsubsection{The Influence of the Presence of Water on the Sound Absorption Coefficient}

The variation in the sound absorption coefficient depending on the amount of water used to obtain WHW80_6_50 and WHW80_6_75 materials is shown in Figure 9. The sound-absorbing properties of the obtained material by wetting with $50 \mathrm{~mL}$ of water (WHW80_6_50) were better than that of the one obtained using $75 \mathrm{~mL}$ of water (WHW80_6_75). 


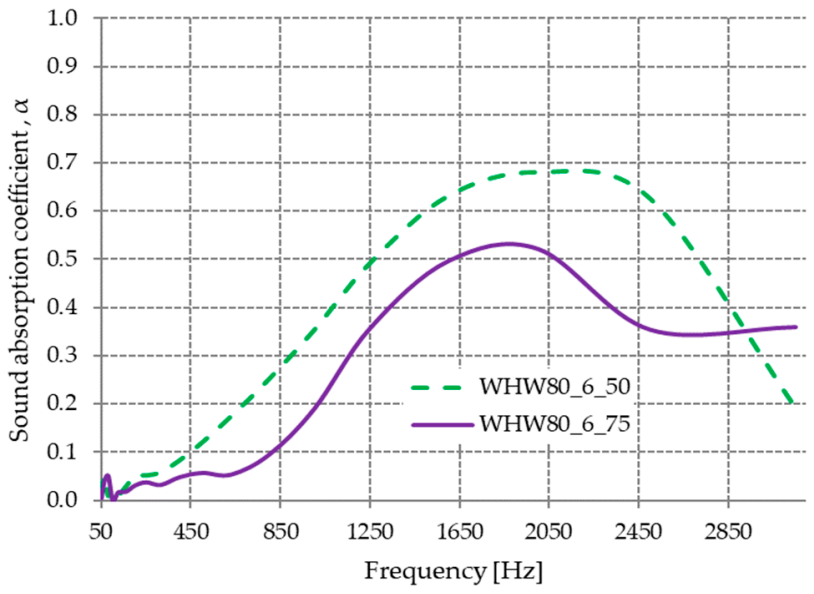

Figure 9. Variation in the acoustic absorption coefficient with the quantity of water.

The decrease in the absorption coefficient values at frequencies below $2850 \mathrm{~Hz}$ for material WHW80_6_75 was due to the change in the thermoplastic properties of wool in the presence of water at $80^{\circ} \mathrm{C}$. On the material's surface, plasticized and glossy areas appeared, which reflected the sound wave and did not allow it to penetrate the material for decreased sound intensity [31].

Polypropylene/jute webs with a thickness of $4.28 \mathrm{~mm}$ and a density of $0.65 \mathrm{~g} / \mathrm{cm}^{3}$ were found to have an acoustic absorption coefficient $\alpha<0.2$ in the frequency range of $100 \div 1600 \mathrm{~Hz}$ [4], while WHW80_6_50 $(2.5 \mathrm{~mm})$ and WHW80_6_75 $(3 \mathrm{~mm})$ with a density of $0.7 \mathrm{~g} / \mathrm{cm}^{3}$ and $0.71 \mathrm{~g} / \mathrm{cm}^{3}$ had a sound absorption coefficient of $\alpha<0.63$ in the frequency range of $100 \div 1600 \mathrm{~Hz}$.

\subsubsection{Influence of Cold/Hot Compression on the Sound Absorption Coefficient}

The influence of the compression mode of the wool fibers (cold or hot) on the acoustic absorption coefficient is highlighted in Figure 10. It can be observed that the materials obtained by hot pressing (WH240_4 and WH120_4) had superior sound-absorbing properties compared to the material obtained by cold pressing (WC40).

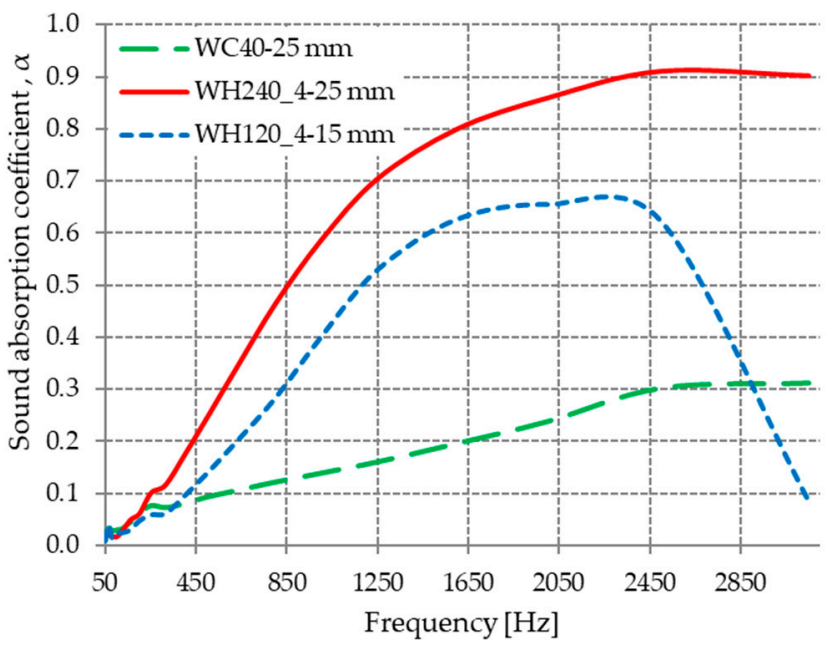

Figure 10. Variation in the acoustic absorption coefficient with frequency.

Considering the density of the hot-pressed materials $\left(0.61 \div 0.65 \mathrm{~g} / \mathrm{cm}^{3}\right)$ was higher than the density of the cold-pressed materials (WC40 $0.02 \mathrm{~g} / \mathrm{cm}^{3}$ ), it can be said that the sound absorption coefficient at high and medium frequencies is higher for materials with higher density [48]. It can be seen from Figure 10 that sample WH240_4 with a density of $0.61 \mathrm{~g} / \mathrm{cm}^{3}$ and a thickness of $25 \mathrm{~mm}$ 
had the best acoustic absorption coefficient values for the entire frequency range analyzed, reaching a maximum of 0.91 at $2500 \mathrm{~Hz}$. In comparison, sample WC40 with a density of $0.02 \mathrm{~g} / \mathrm{cm}^{3}$ and a thickness of $25 \mathrm{~mm}$ had much lower absorption coefficient values, barely reaching 0.3 in the frequency range of $2500 \div 3150 \mathrm{~Hz}$.

\subsubsection{Comparisons with Other Materials}

In order to accentuate the sound-absorbing properties of the materials obtained in this research, a comparative study with other materials in the market (rigid polyurethane foam $40 \mathrm{~mm}$, flexible polyurethane foam $40 \mathrm{~mm}$, and mineral wool $50 \mathrm{~mm}$ ) and a material from the literature (sheep wool mechanically fastened on cloth [21]) was carried out. The results obtained are shown in Figure 11. It can be observed that the obtained material WH240_0.05 (sheep wool hot pressed at $80{ }^{\circ} \mathrm{C}$ with $0.05 \mathrm{MPa}$ ) had the best sound-absorbing properties at frequencies below $2000 \mathrm{~Hz}$, while it had values almost identical to mineral wool in the frequency range of $2000 \div 3200 \mathrm{~Hz}$.

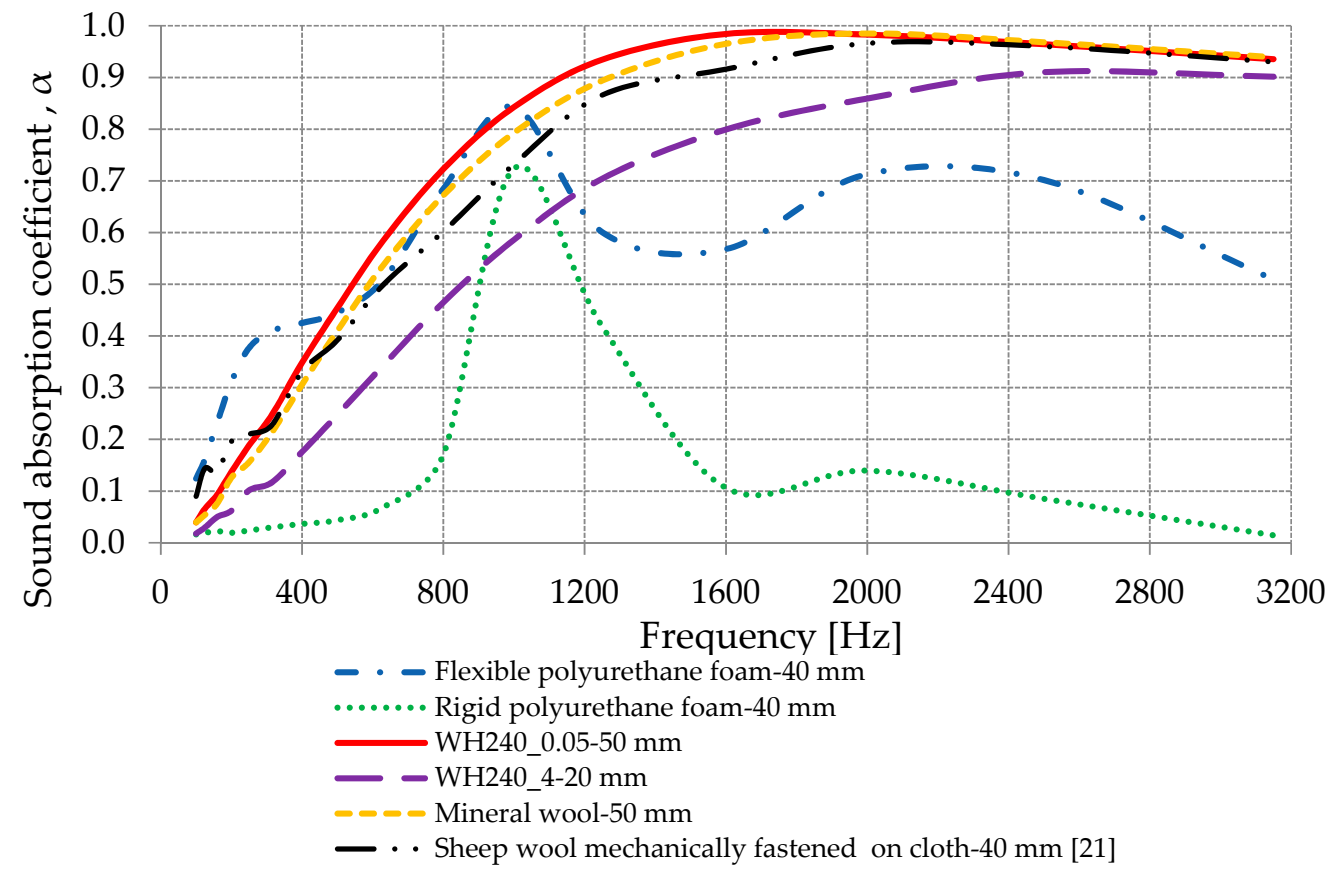

Figure 11. Variation in the acoustic absorption coefficient for WH240_0.05, WH240_4, flexible polyurethane foam, rigid polyurethane foam, and mineral wool.

Compared to the material obtained by Zach et al. [21], also from sheep wool, material WH240_0.05 obtained in this research had better acoustic absorption properties at frequencies higher than $315 \mathrm{~Hz}$.

The material with $80 \%$ sheep wool fibers (40\% first quality and $40 \%$ second quality) and $20 \%$ PET fibers $(50 \mathrm{~mm}$ ) with an acoustic absorption coefficient of more than 0.6 for the frequency range of $800 \div 3150 \mathrm{~Hz}$ [1] had lower acoustic properties compared to WH240_0.05 (50 mm) with an acoustic absorption coefficient of more than 0.72 for the frequency range of $800 \div 3150 \mathrm{~Hz}$.

At frequencies greater than $1200 \mathrm{~Hz}$, material WH240_4 with $20 \mathrm{~mm}$ thickness had an absorption coefficient value greater than the flexible polyurethane foam with $40 \mathrm{~mm}$ thickness. It should be mentioned that the flexible polyurethane foam maintained the best sound-absorbing properties at frequencies below $400 \mathrm{~Hz}$.

\section{Conclusions}

Obtaining environmentally friendly materials with very good acoustic properties from natural and renewable raw materials, such as sheep wool without using any binder, is an important step in 
solving environmental problems and, at the same time, finding new methods of using wool. By simply hot pressing wool, a material that can be processed and manipulated can be obtained.

Hot-pressed materials have a much higher density than cold-pressed materials. The density of materials made from hot-pressed sheep wool increases with increasing pressure.

In this research, material WH240_0.05, which had a $240 \mathrm{~mm}$ layer of wool and $50 \mathrm{~mm}$ thickness and was hot-pressed at $80^{\circ} \mathrm{C}$ and $0.05 \mathrm{MPa}$, had higher sound absorption coefficient values over the entire analyzed frequency range compared to WH120_0.05, which was obtained under the same conditions but with a smaller thickness and a $120 \mathrm{~mm}$ layer of wool.

Due to the thermoplastic properties of wool in the presence of water at a temperature of $80^{\circ} \mathrm{C}$, the sound absorption coefficient of material WHW80_6_75 had lower values at frequencies lower than $2850 \mathrm{~Hz}$ compared to the material with a lower water content.

WH240_0.05, which had $0.01 \mathrm{~g} / \mathrm{cm}^{3}$ density and was pressed at $0.05 \mathrm{MPa}$, had better sound-absorbing properties than WH240_4, which was pressed at $4 \mathrm{MPa}$ and had $0.61 \mathrm{~g} / \mathrm{cm}^{3}$ density. During the compression, the fibers of materials come close, so the open porosity decreases and the compression increases.

The WH240_0.05 material obtained in this study had the best sound-absorbing properties at frequencies below $2000 \mathrm{~Hz}$, while it had values almost identical to mineral wool in the frequency range of $2000 \div 3200 \mathrm{~Hz}$. Thus, hot-pressed sheep wool has better or at least equal sound-absorbing properties as that of mineral wool, which is one of the most widely used sound-absorbing fibrous materials.

The field of use for the obtained materials is wide, but other characteristics will have to be determined.

Author Contributions: Conceptualization, S.I.B.M., A.-E.T. and O.N.; methodology, S.I.B.M.; validation, A.-E.T., H.V. and O.N.; investigation, S.I.B.M. and O.V.; resources, S.I.B.M, A.-E.T., H.V. and O.N.; writing-original draft preparation, S.I.B.M. and A.-E.T.; writing-review and editing, A.-E.T., O.N. and H.V.; supervision, O.N. and O.V. All authors have read and agreed to the published version of the manuscript.

Funding: This research received no external funding.

Conflicts of Interest: The authors declare no conflict of interest.

\section{References}

1. Del Rey, R.; Uris, A.; Alba, J.; Candelas, P. Characterization of sheep wool as a sustainable material for acoustic applications. Materials 2017, 10, 1277. [CrossRef]

2. Asdrubali, F.; D'Alessandro, F.; Schiavoni, S. A review of unconventional sustainable building insulation materials. Sustain. Mater. Technol. 2015, 4, 1. [CrossRef]

3. Schiavoni, S.; D'Alessandro, F.; Bianchi, B.; Asdrubali, F. Insulation materials for the building sector: A review and comparative analysis. Renew. Sustain. Energy Rev. 2016, 62, 988. [CrossRef]

4. Thilagavathi, G.; Pradeep, E.; Kannaian, T.; Sasikala, L. Development of natural fiber nonwovens for application as car interiors for noise control. J. Ind. Text. 2010, 39, 267-278. [CrossRef]

5. Asim, M.; Khalina Abdan, M.; Jawaid, M. A review on pineapple leaves fiber and its composites. Int. J. Polym. Sci. 2015, 950567. [CrossRef]

6. Belakroum, R.; Gherfi, A.; Kadja, M.; Maalouf, C.; Lachi, M. Design and properties of a new sustainable construction material based on date palm fibers and lime. Constr. Build. Mater. 2018, 184, 330-343. [CrossRef]

7. Berardi, U.; Gino, I. Acoustic characterization of natural fibers for sound absorption. Build. Environ. 2015, 94, 840-852. [CrossRef]

8. Elammaran, J.; Hamdan, S.; Ezhumalai, P. Investigation on dielectric and sound absorption properties of banana fibers reinforced epoxy composites. J. Teknol. 2016, 78, 97-103. [CrossRef]

9. Hamzé, K.; Maalouf, C.; Bliard, C.; Moussa, T.; El Wakil, N. Hygrothermal and acoustical performance of starch-beet pulp composites for building thermal insulation. Materials 2018, 11, 1622. [CrossRef]

10. Lim, Z.Y.; Putra, A.; Nor, M.J.M.; Yaakob, M.Y. Sound absorption performance of natural kenaf fibers. Appl. Acoust. 2018, 130, 107-114. [CrossRef]

11. Yian, Z.; Wang, J.; Zhu, Y.; Wang, A. Research and application of kapok fiber as an absorbing material: A mini review. J. Environ. Sci. 2015, 27, 21-32. [CrossRef] 
12. Gagan, B.; Singh, V.K.; Gope, P.C.; Gupta, T. Application and properties of chicken feather fiber (CFF) a livestock waste in composite material development. J. Graph. Era Univ. 2017, 5, 16-24.

13. João, B.; Souza, J.; Lopes, J.B.; Sampaio, J. Characterization of thermal and acoustic insulation of chicken feather reinforced composites. Procedia Eng. 2017, 200, 472-479. [CrossRef]

14. Berardi, U.; Gino, I.; Di Gabriele, M. Characterization of sheep wool panels for room acoustic applications. In Proceedings of the Meetings on Acoustics 22ICA, Buenos Aires, Argentina, 5-9 September 2016. [CrossRef]

15. Dunne, R.; Desai, D.; Sadiku, R.; Jayaramudu, J. A review of natural fibres, their sustainability and automotive applications. J. Reinf. Plast. Compos. 2016, 35, 1041. [CrossRef]

16. Sen, T.; Reddy, H.N.J. Various industrial applications of hemp, kinaf, flax and ramie natural fibres. Int. J. Innov. Manag. Technol. 2011, 2, 192.

17. Spritzendorfer, J. Der Dämmstoff Schafwolle, Energetische Bewertung-CO $\mathrm{CO}_{2}$ Bilanz und Ökobilanz Beratungsagentur für zukunftsfähiges Bauen, Energies; Presse-EGGBI Publikationen: Basel, Schweiz, 2015.

18. Korjenic, A.; Klarić, S.; Hadžić, A.; Korjenic, S. Sheep wool as a construction material for energy efficiency improvement. Energies 2015, 8, 5765-5781. [CrossRef]

19. Dunne, R.; Desai, D.; Sadiku, R. A Review of the Factors that Influence Sound Absorption and the Available Empirical Models for Fibrous Materials. Acoust Aust. 2017, 45, 45. [CrossRef]

20. Asdrubali, F. Survey on the acoustical properties of new sustainable materials for noise control. In Proceedings of the Euronoise 2006, Tampere, Finland, 27-31 May 2006.

21. Zach, J.; Korjenic, A.; Petránek, V.; Hroudová, J.; Bednar, T. Performance evaluation and research of alternative thermal insulations based on sheep wool. Energy Build. 2012, 49, 246-253. [CrossRef]

22. Asis, P.; Mvubu, M.; Muniyasamy, M.; Botha, A.; Anandjiwala, R.D. Thermal and sound insulation materials from waste wool and recycled polyester fibers and their biodegradation studies. Energ. Build. 2015, 92, 161-169. [CrossRef]

23. Pennacchio, R.; Savio, L.; Bosia, D.; Thiebat, F.; Piccablotto, G.; Patrucco, A. Fitness: Sheep-wool and hemp sustainable insulation panels. Energy. Proc. 2017, 111, 287-297. [CrossRef]

24. Del Rey, R.; Alba, J.; Ramis, J.; Sanchis, V. New absorbent acoustics materials from plastic bottle remnants. Mater. Constr. 2011, 61, 547-558. [CrossRef]

25. Ramis, J.; Alba, J.; Del Rey, R.; Escuder, E.; Sanchís, V. New absorbent material acoustic based on kenaf's fiber. Mater. Constr. 2010, 60, 133-143. [CrossRef]

26. Baxter, B.P.; Cottle, D.J. Fiber diameter distribution characteristics of midside (fleece) samples and their use in sheep breeding. Wool Technol. Sheep Breed. 1998, 46, 154-171.

27. Hassan, M.M.; Carr, C.M. A review of the sustainable methods in imparting shrink resistance to wool fabrics. J. Adv. Res. 2019, 18, 39. [CrossRef] [PubMed]

28. Simpson, W.S.; Crawshaw, G.H. Wool: Science and Technology; Woodhead Publishing: Cambridge, UK, 2002.

29. Ibrahim, M.A.; Melik, R.W. Physical parameters affecting acoustic absorption characteristics of fibrous materials. Proc. Math. Phys. Soc. Egypt 1978, 46, 125-130.

30. Gombos, A.M.; Nemes, O.; Soporan, V.F.; Vescan, A. Toward New Composite Materials Starting from Multi-Layer Wastes. STUD U BABES-BOL CHE 2008, LIII, 81.

31. Millington, K.R.; Rippon, J.A. Wool as a high-performance fiber. In Structure and Properties of High-Performance Fibers; Woodhead Publishing: Cambridge, UK, 2017; p. 367.

32. Cellular Plastics and Rubbers-Determination of Apparent Density; Standard ISO 845:2006; ISO: Geneva, Switzerland, 2006.

33. Determination of Sound Absorption Coefficient and Acoustic Impedance with the Interferometer; Standard SR EN ISO 10534-2; Part 2. Transfer Function Method; ISO: Geneva, Switzerland, 2002.

34. Tiuc, A.E.; Vasile, O.; Vermesan, H.; Nemes, O.; Borlea Muresan, S.I. New Multilayered Composite for Sound Absorbing Applications. Rom. J. Acoust. Vib. 2018, 15, 115.

35. Koizumi, T.; Tsujiuchi, N.; Adachi, A. The Development of Sound Absorbing Materials Using Natural Bamboo Fibers, High Performance; WIT Press: Southampton, UK, 2002.

36. Tiuc, A.E.; Nemeş, O.; Vermeşan, H.; Toma, A.C. New sound absorbent composite materials based on sawdust and polyurethane foam. Compos. Part B Eng. 2019, 165, 120-130. [CrossRef]

37. Jimenez-Espadafor, F.J.; Villanueva, J.A.B.; Garcia, M.T.; Trujillo, E.C.; Blanco, A.M. Optimal design of acoustic material from tire fluff. Mater. Des. 2011, 32, 3608-3616. [CrossRef] 
38. Kalauni, K.; Pawar, S.J. A review on the taxonomy, factors associated with sound absorption and theoretical modeling of porous sound absorbing materials. J. Porous Mater. 2019, 26, 1795. [CrossRef]

39. Ersoy, S.; Küçük, H. Investigation of industrial tea-leaf-fiber waste material for its sound absorption properties. Appl. Acoust. 2009, 70, 215-220. [CrossRef]

40. Abdullah, A. Ecological and Economic Attributes of Jute and Natural Fiber for Sustainable Eco-Management; Primeasia University: Dhaka, Bangladesh, 2014.

41. Tiuc, A.E.; Vasile, O.; Vermesan, H. The analysis of factors that influence the sound absorption coefficient of porous materials. RJAV 2014, 11, 105.

42. Asdrubali, F.; D'Alessandro, F.D.; Schiavoni, S. Sound absorbing properties of materials made of rubber crumbs. J. Acoust. Soc. Am. 2008, 35-40. [CrossRef]

43. Nick, A.; Becker, U.; Thoma, W. Improved acoustic behavior of interior parts of renewable resources in the automotive industry. J. Polym. Environ. 2002, 10, 115. [CrossRef]

44. Coates, M.; Kierzkowski, M. Acoustic textiles-lighter, thinner and more absorbent. Tech. Text. Int. 2002, 11, 15.

45. Castagnede, B.; Aknine, A.; Brouard, B. Effects of compression on the sound absorption of fibrous materials. Appl. Acoust. 2000, 61, 173. [CrossRef]

46. Fouladi, M.H.; Nor, M.J.M.; Ayub, M.D. Enhancement of coir fiber normal incidence sound absorption coefficient. J. Comput. Acoust. 2012, 20, 1250003. [CrossRef]

47. Nor, M.J.M.; Ayub, M.; Zulkifli, R. Effect of compression on the acoustic absorption of coir fiber. Am. J. Appl. Sci. 2010, 7, 1285. [CrossRef]

48. Delany, M.E.; Bazley, E.N. Acoustic properties of fibrous absorbent material. Appl. Acoust. 1970, 3, $105-116$. [CrossRef]

(C) 2020 by the authors. Licensee MDPI, Basel, Switzerland. This article is an open access article distributed under the terms and conditions of the Creative Commons Attribution (CC BY) license (http://creativecommons.org/licenses/by/4.0/). 